\title{
ERRATA
}

\section{Epstein-Barr virus can inhibit genotoxin-induced G1 arrest downstream of p53 by preventing the inactivation of CDK2}

Jenny O’Nions and Martin J Allday

Oncogene (2004) 23, 6326. doi:10.1038/sj.onc.1207742

Correction to: Oncogene (2003) 22, 7181-7191. doi:10.1038/sj.onc. 1206838

Due to a production error, Figure $5 \mathrm{f}$ of the above manuscript was not reproduced accurately. The correct figure is given below:

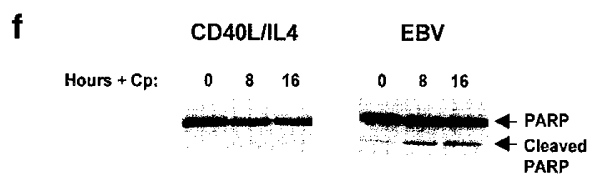

\section{Overexpression of leukocyte marker CD43 causes activation of the tumor-suppressor proteins p53 and ARF}

Lilian Kadaja, Sirle Laos and Toivo Maimets

Oncogene (2004) 23, 6326. doi:10.1038/sj.onc.1207745

Correction to: Oncogene (2004) 23, 2523-2530. doi: 10.1038/sj.onc.1207359

Due to a production error, Figure $6 \mathrm{~b}$ of the above manuscript was not reproduced accurately. The correct figure is given below.

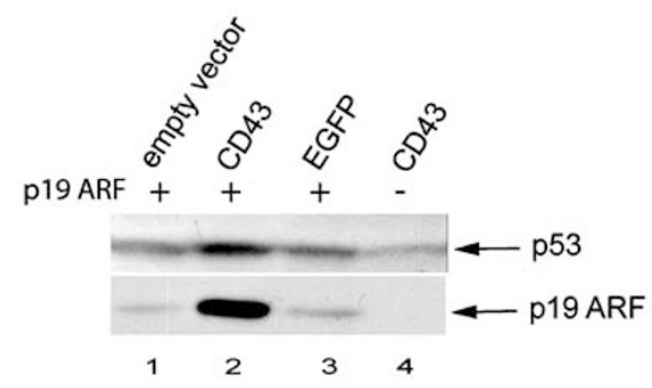

